\title{
Modification of High-Strength and High-Modulus Polyethylene Fiber Surfaces for the Purpose of Dyeing
}

\author{
Hitoshi Fujimatsu ${ }^{\dagger}$ Mitsuhiro Imaizumi, Nobukazu Shibutani, \\ Hisanao USAMI, and Takashi IIJIMA \\ Department of Fine Materials Engineering, Faculty of Textile Science and Technology, \\ Shinshu University, 3-15-1 Tokida, Ueda, Nagano 386-8567, Japan
}

(Received August 29, 2000; Accepted May 8, 2001)

\begin{abstract}
We investigated the dyeing properties of polysiloxane networks formed on high-strength and highmodulus polyethylene fiber after hydroxyl groups were introduced onto the fiber surface by chemical treatment. Hydrogen peroxide in $o$-xylene emulsion in a volume ratio of 1:10 was emulsified by sonication. The emulsion was found to be effective for introduction of hydroxide groups onto the fiber surface. The introduced hydroxide groups reached maximum levels by treatment for approximately $5 \mathrm{~min}$ at $80^{\circ} \mathrm{C}$. The treatment did not influence the tensile strength of the fiber. Utilizing a polysiloxane network in conjunction with the strong fiber surface formed by treating with 3aminopropyltriethoxysilane (APS) solution, the dyeing properties of an anionic dye, C.I. Acid Blue 25 was examined. The dyeing resulted in a bluish polyethylene fiber and the color depended upon the duration of treatment with the APS solution. The method proposed in the present study can be used to dye a polyethylene fiber surface.

KEY WORDS Dyeing / Polyethylene Fiber / Surface Modification / Hydrogen Peroxide / Silane Coupling Agent/ o-Xylene /
\end{abstract}

Compared with other existing fibers, high-strength and high-modulus polyethylene fibers possess advantageous characteristics such as light weight, low resistance, chemical resistance, electrical insulation, and wear resistance. Thus, these fibers have many potential uses. However, it is well known that the bonding and dyeing of polyethylene are difficult processes because polyethylene is non-polar and highly crystalline. The quantities of the high-strength and high-modulus polyethylene are render it even more difficult to process because of the extremely high crystallinity, which is due to the high orientation of polyethylene chains. Although various techniques such as plasma, ${ }^{1-20,22-47}$ flame, ${ }^{48-51}$ chemical, ${ }^{52-62}$ and radiation, ${ }^{63-66}$ treatments can activate polyethylene surfaces, these methods are difficult to apply as regards dyeing polyethylene fibers, as dye molecules do not diffuse into highcrystallized fibers.

Recently, we reported that a metal plate modified with an amino alkyl silane coupling agent could bond with a polyethylene plate in the presence of polyethylene gels. ${ }^{67}$ In that study, we pointed out that polysiloxane networks formed on the metal surface under definite conditions, and that the product has a flexible structure and spaces favorable for the permeation of polyethylene chains, which forms an effective adhesive. Accordingly, polysiloxane networks formed from silane coupling agents are expected to be useful, both in the dyeing process, as well as in the field of diffusion. ${ }^{67}$

${ }^{\dagger}$ To whom correspondence should be addressed.
In the present study, we investigated the dyeing properties of polysiloxane networks formed on highstrength and high-modulus polyethylene fiber after hydroxyl groups were introduced onto the fiber surface by chemical treatment.

\section{EXPERIMENTAL}

\section{Materials}

High-strength and high-modulus polyethylene fiber (TEKMILON NA310) with a diameter of $30 \mu \mathrm{m}$ was supplied by Mitsui Petrochemical Industry Corp. and was used in the present experiments. Hydrogen peroxide and sulfuric acid of Wako reagent grade were used as chemical reagents for the surface modification of the polyethylene fiber. $o$-xylene of Wako reagent grade was used as the adjunct reagent for the surface modification of the polyethylene fiber. The silane-coupling agent used for the surface treatment of the polyethylene fiber was 3-aminopropyltriethoxysilane of Chisso Corp. C.I. Acid Blue 25 (Mitsubishi Chemical Corp.), which was used for the dyeing process, was purified by ordinal recrystallization before it was used.

\section{Methods}

Chemical Treatments for Introducing Hydroxide Groups onto Polyethylene Fiber

Treatment solution 1: $30 \%$ hydrogen peroxide solution was used as the solution for the surface treatment. The hydrogen peroxide solution of $30 \mathrm{~mL}$ was prepared in a capped vessel in which $10 \mathrm{~cm}$ long polyethylene 
fibers were immersed. The fibers were treated in a thermobath controlled at $30^{\circ} \mathrm{C}$ for a variety of durations from 0.5 to $64 \mathrm{~min}$. The chemical and mechanical properties of the treated fibers were measured after they were rinsed in a stream of water.

Treatment solution 2: A hydrogen peroxide-sulfuric acid mixture in a volume ratio of 1:1 was used as the solution for the surface treatment. The polyethylene fibers were immersed in $30 \mathrm{~mL}$ of the mixture, which was kept at a controlled temperature of $30^{\circ} \mathrm{C}$ for $1 \mathrm{~h}$.

Treatment solution 3: A hydrogen peroxide in $o-$ xylene emulsion in a volume ratio of 1:10 was used as the solution for the surface treatment. $30 \mathrm{~mL}$ of $o-$ xylene-hydrogen peroxide mixture in a volume ratio of 10:1 was sonicated for 3 min using a Shimadzu ultrasonic disintegrater USP-300. The polyethylene fibers were immersed in $30 \mathrm{~mL}$ of the emulsion, which was kept at $80^{\circ} \mathrm{C}$ for $1 \mathrm{~h}$.

\section{Chemical Treatment for forming a Siloxane Network on a Polyethylene Fiber Surface}

A $1.0 \mathrm{vol} \%$ APS solution, in which the solvent was water-ethanol mixture (the ethanol to water ratio was equal to a volume ratio of 7:3), was used for forming a siloxane network on polyethylene fiber surface. Polyethylene fibers were treated with the solution, which was kept at $30^{\circ} \mathrm{C}$ for durations ranging from 10 $\min$ to $180 \mathrm{~min}$. The treated polyethylene fibers were rinsed with a stream of water before subsequent processing.

\section{ATR-FT-IR Measurement}

To examine whether or not desired functional groups were introduced onto a polyethylene fiber, an ATR-FTIR measurement was carried out. The apparatus used for the measurement was a Nicolet OMNI-Sampler.

\section{Measurement of Mechanical Properties}

Mechanical properties of polyethylene fibers treated with hydrogen peroxide solution were measured using a Shimadzu AUTO GRAPH AGS-5kND, at a tensile speed of $10 \mathrm{~mm} \mathrm{~min}^{-1}$.

\section{Dyeing}

C.I. Acid Blue 25 was dissolved in water until the solution was saturated. Acetic acid was added in small amounts to the solution. Polyethylene fibers that have been modified with the APS solution were then dyed at $80^{\circ} \mathrm{C}$ for $30 \mathrm{~min}$. To remove the dye that had adhered to the fiber surface, the polyethylene fibers were rinsed with flowing water after they had been dyed.

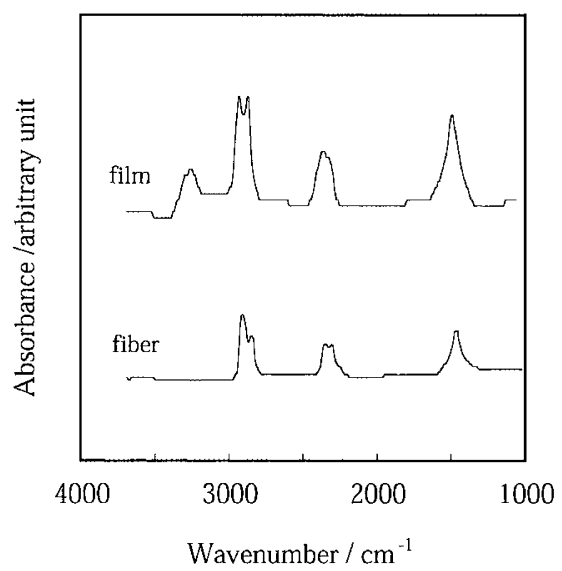

Figure 1. ATR-FT-IR spectra of linear low-density polyethylene film and polyethylene fiber treated with hydrogen peroxidesulfuric acid mixture in a volume ratio of $1: 1$ for $1 \mathrm{~h}$ at $30^{\circ} \mathrm{C}$.

\section{ATR-Visible Spectra Measurement}

To examine the dyeing properties of polyethylene fibers, ATR-visible spectra were measured using a Shimadzu Multi-Purpose Spectrophotometer MPS-2000, which was equipped with a mirror reflection-type ATR apparatus.

\section{RESULTS AND DISCUSSION}

\section{Introduction of Hydroxide Groups on a Polyethylene Fiber Surface}

To examine where the FT-IR spectrum change occurs when hydroxide groups are introduced onto polyethylene fibers, FT-IR measurement of polyvinyl alcohol film, having the structure of added hydroxide groups on polyvinyl chains, was first carried out. From the obtained spectrum, the absorbance band assigned to the $\mathrm{O}-\mathrm{H}$ stretching vibration was observed as a broad peak centered at $3320 \mathrm{~cm}^{-1}, 75$ as shown in Figure 1. Accordingly, subsequent experiments were carried out with a focus on the band in the vicinity of $3320 \mathrm{~cm}^{-1}$.

In ATR-FT-IR spectra of polyethylene fibers treated with hydrogen peroxide solution, a band in the vicinity of $3320 \mathrm{~cm}^{-1}$ was not observed, even in the spectra of polyethylene fibers treated for $60 \mathrm{~min}$. This indicates that the introduction of hydroxide groups onto polyethylene fiber is difficult via this method.

Subsequently, a strong oxidizing agent was used to treat the fiber surface; for this agent sulfuric acid was added to hydrogen peroxide in place of hydroxide solution. This method has been used for modifying the surface of polyethylene moldings and films. ${ }^{52-62}$ The effect of this treatment was also examined in the presence of an unoriented linear low-density polyethylene film. The results are shown in Figure 1. For the polyethylene film, a band in the vicinity of $3320 \mathrm{~cm}^{-1}$ is eas- 


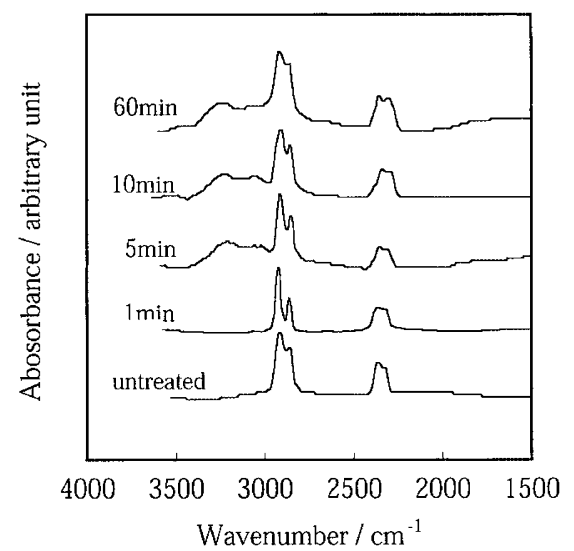

Figure 2. ATR-FT-IR spectra of polyethylene fibers treated with $o$-xylene-hydrogen peroxide emulsion in a volume ratio of $10: 1$ at $80^{\circ} \mathrm{C}$ for a variety of durations.

ily observed. However, in the case of the polyethylene fiber, evidence for the introduction of a hydroxide group could not be confirmed. These results indicate that the mixture that added sulfuric acid to hydrogen peroxide is ineffective on treating highly oriented polyethylene fibers, although it does act effectively as a strong oxidizing agent of the polyethylene film surface.

These findings suggest that if the highly orientated polyethylene chain on the polyethylene fiber surface is disoriented, then hydroxide groups may be introduced on the polyethylene fiber surface, as well as on polyethylene film.

A solution of this problem presented itself on the basis of information obtained from our previous studies $^{68-74}$ of polyethylene gels. When polyethylene and a solvent coexist, a melting point depression of the polyethylene is induced. A similar effect may be expected to occur even for high-strength and highmodulus polyethylene fiber. In the present study, it was sufficient to partially swell the polyethylene fiber surface. Then, a $o$-xylene-hydrogen peroxide mixture was prepared so that the oxidation reaction of the polyethylene fiber surface was allowed to proceed in conjunction with simultaneous swelling. However, since hydrogen peroxide is immiscible with $o$-xylene, the mixture remained separated unless further treatment was initiated. Accordingly, the mixture was emulsified by the ultrasonic method. $o$-Xylene-hydrogen peroxide mixture in a volume ratio of 10:1 was determined as the mixture having the maximum ratio, at which hydrogen peroxide can be contained in $o$-xylene without the separation of liquids occurring during treatment at $80^{\circ} \mathrm{C}$. The resulting ATR-FT-IR spectra are shown in Figure 2. A broad peak centered at $3320 \mathrm{~cm}^{-1}$ assigned to the $\mathrm{O}-\mathrm{H}$ stretching vibration was clearly observed, even when the mixture was treated for $5 \mathrm{~min}$. To clarify the time dependence of the introduced amount of hydrox-

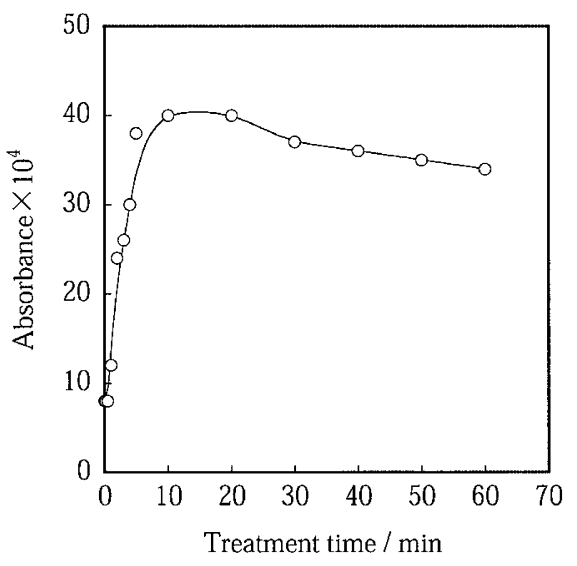

Figure 3. Treatment time dependence of the absorbance at $3320 \mathrm{~cm}^{-1}$ in ATR-FT-IR spectra of polyethylene fibers treated with $o$-xylene-hydrogen peroxide emulsion in a volume ratio of 10:1 at $80^{\circ} \mathrm{C}$.

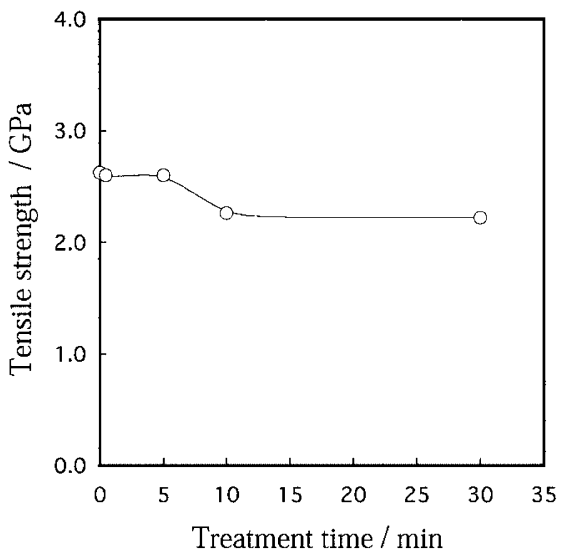

Figure 4. Treatment time dependence of the tensile strength of polyethylene fibers treated with $o$-xylene-hydrogen peroxide emulsion in a volume ratio of $10: 1$ at $80^{\circ} \mathrm{C}$.

ide, the values of absorbance at $3320 \mathrm{~cm}^{-1}$ were plotted against the treatment time, as shown in Figure 3. The absorbance increased rapidly, and decreased gradually through the maximum value at around 10 min of treatment time. The results demonstrate that the introduction of a hydroxide group onto the polyethylene fiber surface attained saturation at approximately $10 \mathrm{~min}$.

\section{Mechanical Properties of Polyethylene Fiber Treated with o-Xylene-hydrogen Peroxide Mixture}

To examine the influence of the above chemical treatment on the mechanical properties of polyethylene fiber, the tensile strength of the fiber product was measured. The results are given in Figure 4. The tensile strength remained at its initial value up to at least 5 min of treatment, and after that time, it tended to decrease somewhat with an increase in treatment duration. Changes in tensile strength behavior are considered to reflect changes in the polyethylene fiber surface due to chemical treatment. Taking into account the results, the optimum reaction conditions for introducing a 


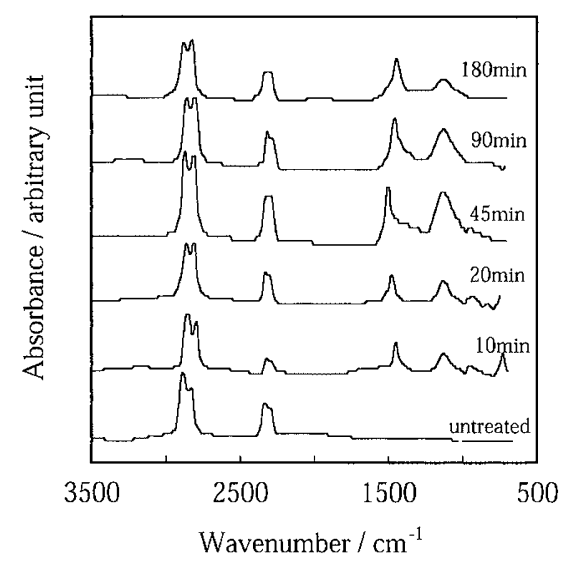

Figure 5. ATR-FT-IR spectra of polyethylene fibers treated with $1.0 \mathrm{vol} \%$ APS solution kept at $30^{\circ} \mathrm{C}$ for a variety of durations.

hydroxide group onto polyethylene fiber surface, without a reduction of tensile strength, was determined to be $5 \mathrm{~min}$ at $80^{\circ} \mathrm{C}$.

Formation of a Siloxane Network on a Polyethylene Fiber Surface by Treatment with APS Solution

ATR-FT-IR spectra of polyethylene fibers treated with $1.0 \mathrm{vol} \%$ APS solution for various amounts of time are shown in Figure 5. As the absorbance band assigned to the $\mathrm{Si}-\mathrm{O}-\mathrm{Si}$ stretching vibration was observed as a broad peak centered at $1136 \mathrm{~cm}^{-1},{ }^{75}$ it was apparent that a polysiloxane structure had been formed on the polyethylene fiber surface. To clarify the time dependence of the formed amount of siloxane bonding, the values of absorbance at $1136 \mathrm{~cm}^{-1}$ were plotted against treatment time, as shown in Figure 6. The absorbance increased with treatment time, and decreased through a maximum in the vicinity of $90 \mathrm{~min}$. These results demonstrate that treatment for 90 min leads to the highest density of siloxane bonding to the polyethylene fiber.

\section{Dyeing Properties of Polyethylene Fibers Treated with APS Solution}

Polyethylene fibers treated under the conditions described above were dyed in C.I. Acid Blue 25 aqueous solution at $80^{\circ} \mathrm{C}$ for $30 \mathrm{~min}$. Each fiber was clearly dyed blue. To clarify differences in dyeing these fibers, ATR-visible spectra were measured. The absorbance at the maximum absorption wavelength of the dye was plotted against the time of treatment with APS solution, as shown in Figure 7. The relative absorbance differences can be seen in Figure 7, although the quantitative values are ambiguous. The absorbance curve was found to have a maximum in the vicinity of $50 \mathrm{~min}$, which was within the range of this experiment. The results regarding the maximum time are in disagreement with those of the absorbance curve for the $\mathrm{Si}-\mathrm{O}-$ Si band. This finding suggests that a siloxane network,

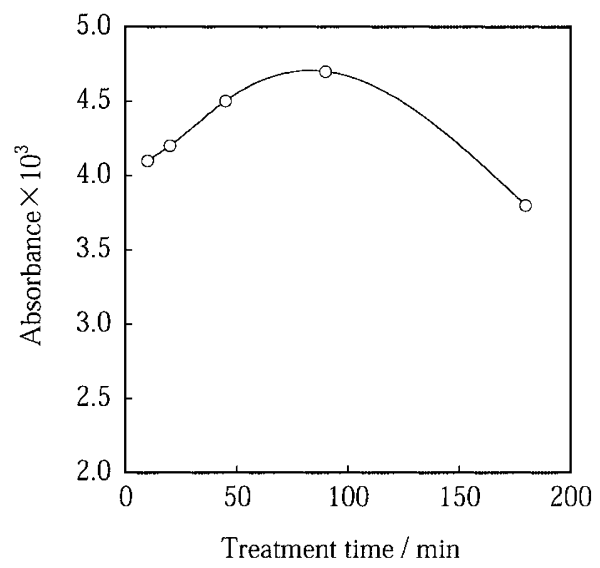

Figure 6. Treatment time dependence of the absorbance at $1136 \mathrm{~cm}^{-1}$ in ATR-FT-IR spectra of polyethylene fibers treated with $1.0 \mathrm{vol} \%$ APS solution at $30^{\circ} \mathrm{C}$.

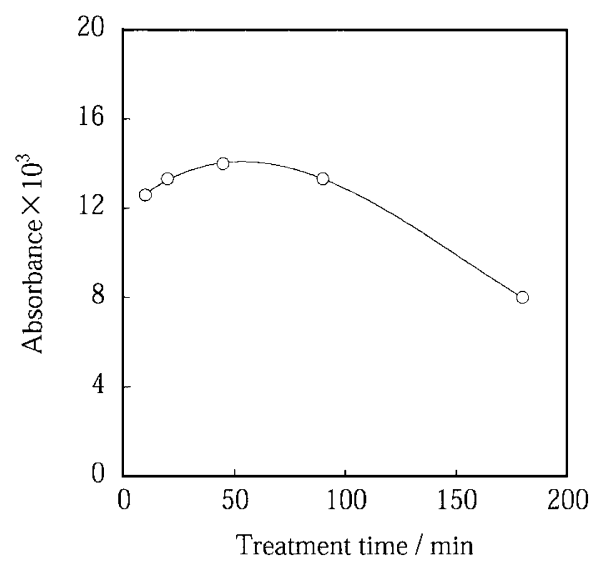

Figure 7. Relationship between absorbance at $600 \mathrm{~nm}$ in ATRvisible spectra of polyethylene fibers dyed with C.I. Acid Blue 25 and the time treated with $1.0 \mathrm{vol} \%$ APS solution at $30^{\circ} \mathrm{C}$.

formed by treating the mixture with APS solution, influences the dyeing properties of the fiber. Details concerning the relationship between dyeing properties and the structure of the siloxane network need to be investigated further.

Acknowledgment. This work was supported by Grant-in-Aid for COE Research (10CE2003) by the Ministry of Education, Science, Sports and Culture of Japan.

\section{REFERENCES}

1. J. C. Von der Heide and H. L. Wilson, Mod. Plastics, 38, 199 (1961).

2. K. Rossmann, J. Polym. Sci., 19, 141 (1956).

3. J. R. Hall, C. A. L. Westerdahl, A. T. Devine and M. J. Bodnar, J. Appl. Polym. Sci., 13, 2085 (1969).

4. C. Y. Kim, J. Evans, and D. A. I. Goring, J. Appl. Polym. Sci., 15, 1365 (1971).

5. A. R. Blythe, D. Briggs, C. R. Kendall, D. G. Rance, and V. J. I. Zichy, Polymer, 19, 1273 (1978).

6. D. Briggs, J. Adhes., 13, 287 (1982).

7. M. M. Kadash and C. G. Seefried, Jr., Plast. Eng., 41, 45 (1985). 
8. F. C. Schwab and M. A. Kadash, J. Plast. Film Sheeting, 2, 119 (1986)

9. M. Rasch and D. Briggs, in "Adhesion", K. W. Allen, Ed., Applied Science, London, 1982, vol. 6, pp 111-120.

10. B. Westerlind, A. Larsson, and M. Rigdahl, Intl. J. Adhes. Adhes., 7, 141 (1987).

11. A. Anon, Plastverarbeiter, 38, 63 (1987).

12. L. Mascia and G. E. Carr, Plast. Rubber Process. Appl., 9, 133 (1988).

13. G. E. Ealer, W. C. Harris, and S. B. Samuels, J. Plast. Film Sheeting, 6, 17 (1990).

14. H. P. Schreiber and F. St. Germain, J. Adhes. Sci. Technol., 4, 319 (1990).

15. A. Savolanien and J. Kuusipalo, Tappi J., 73, 133 (1990).

16. G. E. Ealer, S. B. Samuels, and W. C. Harris, Tappi J., 73, 145 (1990).

17. K. Bartos, Przegl. Wlok., 43, 417 (1989).

18. J. A. Lanauze and D. L. Myers, J. Appl. Polym. Sci., 40, 595 (1990)

19. M. Morra, E. Occhiello, L. Gila, and F. Garbassi, J. Adhes., 33, 77 (1990).

20. W. L. Wade, Jr., R. J Mammone, and M. Binder, J. Appl. Polym. Sci., 43, 1589 (1991).

21. P. J. C. Cheppell, J. R. Brown, G. A. George, and H. A. Willis, Surf. Interface Anal., 17, 143 (1991).

22. S. Corn, K. P. Vora, M. Strobel, and C. S. Lyons, J. Adhes. Sci. Technol., 5, 239 (1991).

23. D. F. Kagan and V. V. Prokopenko, Plast. Massy, 16, 39 (1991).

24. L. Dorn and W. Wahono, Kunststoffe, 81, 764 (1991).

25. R. Foerch, J. Izawa, and G. Spears, J. Adhes. Sci. Technol., 5, 549 (1991).

26. Z. F. Li, A. N. Netravali, and W. Sachse, J. Mate. Sci., 27, 4625 (1992).

27. B. Tissington, G. Pollard, and I. M. Ward, Composite Sci. Technol., 44, 185 (1992).

28. G. A. George and H. A. Willis, High Perform. Polym., 1, 335 (1989).

29. S. Gao and Y. Zeng, J. Appl. Polym. Sci., 47, 2065 (1993).

30. S. Gao and Y. Zeng, J. Appl. Polym. Sci., 47, 2093 (1993).

31. D. N. Hild and P. Schwartz, J. Adhes. Sci. Technol., 6, 897 (1992).

32. M. Zenkiewicz, Zesz. Nauk. Politech. Slask., Mech., 98, 130 (1990)

33. J. R. Brown, P. J. C. Chappell, and Z. Mathys, J. Mater. Sci., 27, 6475 (1992).

34. M. Osterhold and A. Wiechers, Materialpruefung, 35, 178 (1993)

35. Y. Yao, X. Liu, and Y. Zhu, J. Adhes. Sci. Technol. 7, 63 (1993)

36. M. H. Hansen, M. F. Finlayson, M. J. Castille, and J. D. Goins, Tappi J., 76, 171 (1993).

37. C. M. G. Carlsson and K. S. Johansson, Surf. Interface Anal., 20, 441 (1993).

38. Y. Chaoting, S. Gao, and Q. Mu, J. Mater. Sci., 28, 4883 (1993)

39. V. C. Della, L. Fambri, R. Fenner, C. Migliaresi, and A. Pegoretti, J. Mater. Sci., 29, 3919 (1994).

40. W. S. Gutowski and E. R. Pankevicius, Composite Interfaces, 1, 141 (1993).
41. S. Sapieha, J. Cerny, J. E. Klemberg-Sapieha, and L. Martinu, J. Adhes., 42, 91 (1993).

42. F. P. M. Mercx, Polymer, 35, 2098 (1994).

43. S. O'Kell, T. Henshaw, G. Farrow, M. Aindow, and C. Jones, Surf. Interface Anal., 23, 319 (1995).

44. D. M. Brewis, I. Mathieson, and M. Wolfensberger, Intl. J. Adhes. Adhes., 15, 87 (1995).

45. I. Sutherland, R. P. Popat, D. M. Brewis, and R. Calder, J. Adhes., 46, 79 (1994).

46. P. Masse, J. P. Cavrot, P. Francois, J. M. Lefebvre, and B. Escaig, Polym. Compos., 15, 247 (1994).

47. J. J. Ziccarelli, Mod. Plastics, 40, 125 (1962).

48. E. Piiroja and A. Dankovics, Plast. Massy, 7, 35 (1982).

49. E. Piiroja and H. Lippmaa, Acta Polymerica, 35, 669 (1984).

50. E. Sheng, I. Sutherland, D. M. Brewis, R. J. Heath, and R. H. Bradley, J. Mater. Chem., 4, 487 (1994).

51. W. H. Schrader and M. J. Bodnar, Plast. Technol., 3, 988 (1957).

52. M. J. Bodnar and W. J. Powers, Plast. Technol., 4, 721 (1958).

53. M. D. Anderson and M. J. Bodnar, Adhesive Age, 9 (Nov.), 26 (1964).

54. D. A. Olsen and A. J. Osteraas, J. Polym. Sci., Polym. chem. Ed., 7, 1913 (1969).

55. P. Blais, D. J. Carlsson, G. W. Csullog, and D. M. Wiles, J. Colloid Interface Sci., 47, 636 (1974).

56. K. Saito, Nippon Setchaku Kyoukaish, 27, 302 (1983).

57. C. Fonseca, J. M. Perena, J. G. Fatou, and A. Bello, J. Mater. Sci., 20, 3283 (1985).

58. A. Chew, R. H. Dahm, D. M. Brewis, D. Briggs, and D. G. Rance, J. Colloid Interface Sci., 110, 88 (1986).

59. M. Deyme, J. Colloid Interface Sci., 112, 183 (1986)

60. C. G. Golander and B. A. Sultan, J. Adhes. Sci. Technol., 2, 125 (1988)

61. V. V. Arslanov, A. A. Cherezov, A. E. Chalykh, and V. A. Ogarev, Vysokomol. Soedin., Ser: B, 25, 437 (1983).

62. E. S. Turkina and E. D. Yakhnin, Vysokomol. Soedin., Ser: A, 27, 643 (1985).

63. J. T. Simpson, Radiat. Phys. Chem., 25, 483 (1985).

64. K. Kato, J. Appl. Polym. Sci., 19, 951 (1975).

65. D. K. Owens, J. Appl. Polym. Sci., 19, 3315 (1975).

66. H. Fujimatsu, K. Iyo, H. Usami, and S. Ogasawara, Composite Interfaces, (in press).

67. H. Fujimatsu and S. Kuroiwa, Colloid Polym. Sci., 265, 747 (1987).

68. H. Fujimatsu and S. Kuroiwa, J. Colloid Interface Sci., 123, 309 (1988)

69. H. Fujimatsu, S. Ogasawara, N. Satoh, K. Komori, and S. Kuroiwa, Colloid Polym. Sci., 267, 500 (1989).

70. H. Fujimatsu, S. Ogasawara, N. Satoh, K. Komori, Y. Matsunaga, and S. Kuroiwa, Colloid Polym. Sci., 268, 143 (1990).

71. H. Fujimatsu, S. Ogasawara, and S. Kuroiwa, Colloid Polym. Sci., 268, 28 (1990).

72. H. Fujimatsu, S. Ogasawara, and S. Kuroiwa, J. Adhes. Sci. Technol., 4, 35 (1990).

73. H. Fujimatsu, N. Satoh, S. Yamamoto, H. Usami, S. Ogasawara, and S. Kuroiwa, Composite Interfaces, 2, 117 (1994).

74. C. A. Finch, "Polyvinyl Alcohol", John Wiley \& Sons, Inc., London, 1973, pp 214-216.

75. D. G. Kurth and T. Bein, Langmuir, 11, 3061 (1995). 